\title{
A new communication aid for mechanically ventilated patients
}

\author{
Mark van den Boogaard RN, intensive care nurse, AOV-Intensive Care, St. Radboud University Medical Centre, \\ Nijmegen, The Netherlands Arno van Grunsven RN, intensive care nurse, AOV-Intensive Care, St. Radboud \\ University Medical Centre, Nijmegen, The Netherlands
}

E-mail: m.vandenboogaard@ic.umcn.nl * a.vangrunsven@ic.umcn.nl

Key words: communication aid critical care intubated mechanical ventilation

\section{SUMMARY \\ * Communication with ventilated patients is often labori- ous and can be a source of frustration for the patient, the family and caregivers. \\ * The ventilated patient frequently has difficulty with writ- ing, and use of other aids such as the alphabetical letter board often fail. \\ * A new 'intelligent' keyboard, which was developed as an aid for people with a handicap, was evaluated by vetilated patients in our centre and compared with the letter board. \\ * Patients and nurses considered the keyboard to be signifcantly better than the traditional letter board. \\ * As a consequence of this evaluation, a special 'commu- nication car' was developed, which is now used in our critical care units.}

\section{INTRODUCTION}

Ventilated patients are unable to converse in a normal manner. This can affect communication with physicians, nurses, paramedics and family and friends. Often this period of inability to communicate becomes a negative experience that patients remember for a long time. It can be an exhausting experience (Hafsteindottir, 1996).

In their study, Bergbom and Haljamae (1989) found that $47 \%$ of ventilated patients $(n=158)$ who could remember this period were frightened and fearful. Their feelings were statistically significant and were related to fear, panic and insecurity. Patients indicated that the most important factor was their inability to communicate. Not only is communication problematic for patients but also for nurses, who can find attempts to communicate time consuming and frustrating, often producing an unsatisfactory outcome (Usher \& Monkley, 2001)

\section{COMMUNICATION AIDS}

Most communication aids used currently in intensive care, such as sign language, letter boards and lip-reading, are imperfect. Sign language and lip-reading are particularly difficult for all concerned, and to be effective, require years of experience. To compli- cate matters further, when patients try to ask a question or make a statement, it is often not directly related to their health. This makes it very difficult to guess what is being said. Memory and the ability to concentrate are also important factors. In our experience, when using the letter board, patients often do not remember - after only three or four letters - which letters they have indicated.

Sign language and letter boards cost both parties a lot of time and effort. Attempts to understand precisely what the patient means often end in frustration on the part of the patient. In practice, lack of nurses' time can also be an issue, and evaluation of the quality of communication by nurses and patients is not always the same. For example, one study found that only 13 out of 22 patients felt that nurses understood what they meant, whereas the nurses indicated they had functional communication with 19 of the patients (Wojnicki-Johansson, 2001). In this study, nurses were more satisfied with the level of communication than patients.

If a patient is able to write clearly, this tends to be the simplest, most effective, and cheapest way for a ventilated patient to communicate. However, this is rarely the case. Attempts at writing often resemble the trail of 'the spider that just crawled out of the ink pot!' There are many reasons for this, such as hand oedema, insufficient muscle power, and neurological effects due to trauma and sedation.

Our experience is that intensive care unit patients, especially those who are awake and alert but unable to communicate verbally, can become frustrated with their inability to communicate effectively. This can also be problematic for staff and relatives. Other critical care units have reported similar experiences (Bloo, 2001).

Having recognised communication with ventilated patients as an ongoing problem in our critical care units, we searched the market for a communication aid that might help. One possible solution was found in the field of healthcare for people with a handicap. We discovered a Dutch company that manufactured a range of communication aids and, in particular, one piece of equipment that we felt could possibly solve or reduce our problem of communication with ventilated patients. It was a modified keyboard, used with a standard computer or notebook. 


\section{THE SOLUTION}

The 'intelligent' keyboard is large and easy to operate. It comes with both USB and PS2 connections, making it simple to connect to a computer. It has the same functionality as a normal keyboard, but with the addition of extra values, depending on the template used, of which there are several:

* a number of templates with a 'QWERTY' layout (more or less expanded);

* a template with mouse functionality;

* a numeric template;

* an alphabetical template.

It is also supplied with a SET-UP template, which amongst other things, enables the recurring speed and repetition keys of the keyboard to be set to individual preferences. It is possible to change templates without causing any problems as they are recognised immediately by the 'intelligent' keyboard.

In our intensive care unit, we chose the alphabetical template because it is easier for people who are unfamiliar with typing to find the letters. The keys are covered by a transparent, synthetic board with holes made for each key. Each template has its own easy-to-clean cover. The advantage of the cover is that it is possible for the patients to rest their hands on it without touching a key. It also prevents accidental touching of more than one key at a time. With one finger through a hole, the desired letter can be activated by light touch.

Because the keyboard is connected to a computer (in our case, a notebook) the typed letters appear on the screen. This makes it simple for both parties to read the text, and gives direct and immediate feedback to the patient and the person they are communicating with. Specific computer skills are not required, and the notebook or computer is configured to start up with a default word processing programme such as Microsoft Word or Notebook. Programmes such as these allow simple adaptations to be made to the font type and size of the letters, requirements that will vary

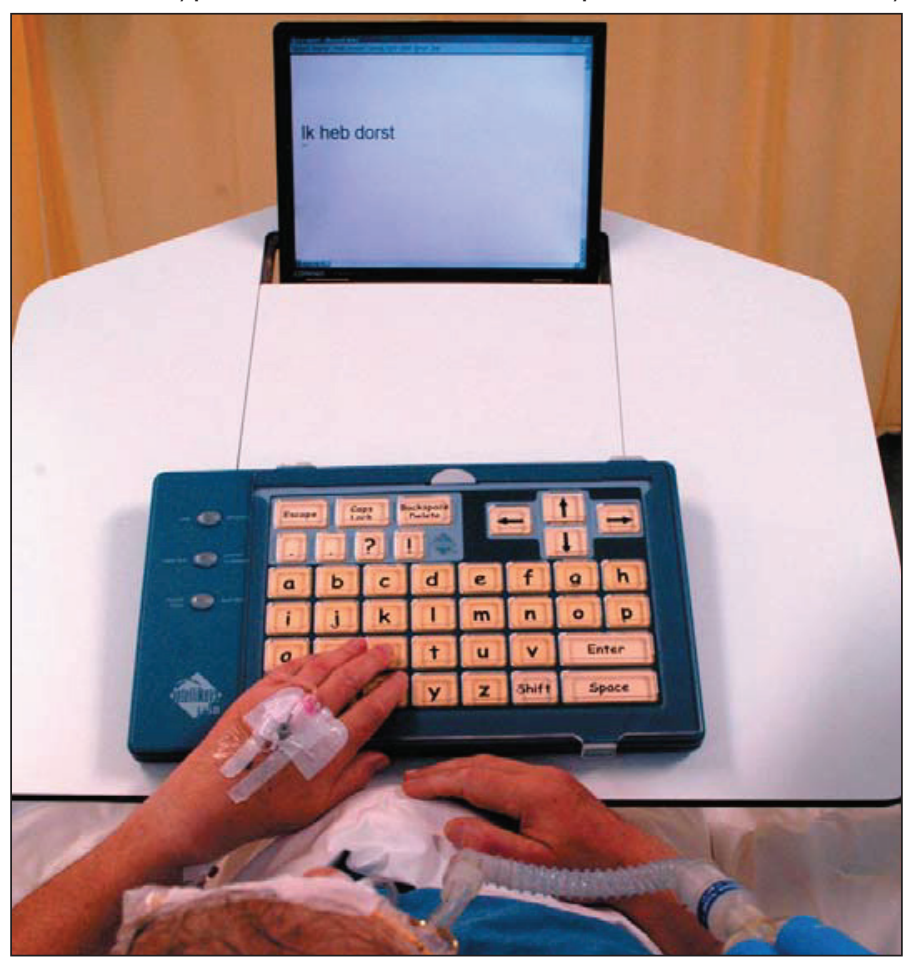

Photo 1. The patient gets visual feedback of what he is typing. with different patients. A patient's text preferences are stored easily in a normal.dot template for future use. Additionally, the benefit of using a computer means that text can either be stored on a disk or printed.

\section{EVALUATION}

Evaluation was conducted not as a research study but as an information gathering exercise to inform practice development. The 'intelligent' keyboard was evaluated in our unit by nine ventilated patients over a period of 13 weeks. The inclusion criteria were that the patient was aged 16 and above, was intubated, was able to communicate, and could read and write in Dutch.

Having gained consent from both patients and nurses, the keyboard was compared with the letter board. Although we could have made comparisons with other communication aids, we chose the letter board because it was used most frequently in our practice. We were also concerned that evaluation of more than two communication aids could have been taxing or confusing for patients, with the potential for uncertainty about their preference. Both patients and nurses evaluated both aids.

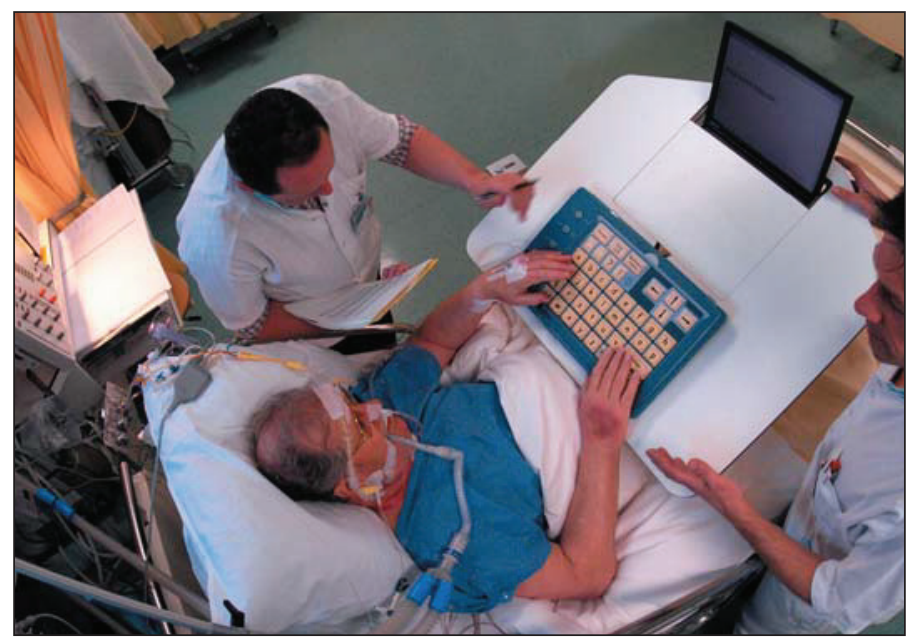

Photo 2. The patient is communicating with nurses.

The patient was required to ask the nurse three out of ten simple questions/statements from a pre-determined list (Table 1). The questions/statements were chosen randomly by the patient. Three questions/statements were made with the help of the letter board, followed by three different ones using the keyboard. Which aid was used first was determined by random selection (from an envelope). The two communication aids were tested immediately after each other. The patient was not required to translate the questions/statements exactly. A successful communication was judged according to the correct interpretation of what the patient meant by the nurse.

Patients evaluated their satisfaction, the convenience of use and the amount of effort required to work with each communication aid. Nurses were required to evaluate similarly. They were also asked if they would use the 'intelligent' keyboard if it was purchased for the critical care units (see Table 2).

After the evaluation, patients were able to use the keyboard for a longer period if they wished, unless it was required for another patient to participate in the evaluation. In the event, all patients chose to continue using it. 

When does the Doctor come? I want to speak to the Doctor My foot hurts.

My wound is sore.

I'm thirsty.

I want to watch television.

I want to listen to the radio.

Can I get something to sleep?

May I have a painkiller?

Table 1. Questions and statements.

\section{DISCUSSION AND CONCLUSIONS}

Although not all questions were answered fully in the evaluation, it can be seen clearly from Table 2 that, in general, both the patients and the nurses were more satisfied with the keyboard than the alphabetical letter board. The keyboard scored more highly on effort, convenience of use and satisfaction. These findings were further supported by the patients' continued use of the keyboard after the evaluation, with some patients who were able to write preferring to use it. Although this evaluation was relatively small, it was sufficient to demonstrate the positive benefits of using the keyboard over the letter board.

To use this keyboard effectively, the patient must have some muscle power. This means that some patients will be unable to use it, especially those with neuropathies. In addition, it is important to recognise that patients may need some time to become accustomed to using the keyboard, especially older people who may never have used a computer before. In our experience, with a little practice, improvements are made quickly, and as the patients' skill in its use becomes more proficient they become more enthusiastic.

A possible development is that we could design our own templates. Special software is required for this and is available from the manufacturer. The keyboard needs to 'know' where, on any new template, the defined characters, letters or even pictograms are situated so that they can be displayed correctly on the screen when activated. We have not yet experimented with this. Initially we want to develop the keyboard further for adults to use, though we also hope, in the future, to develop something for children using symbols and pictograms. To purchase an expensive solution only for this purpose is, in our opinion, questionable. However, if the communication aid is part of a computer-based package that includes other applications such as games, educational programmes or internet access, it becomes a more financially viable investment.

During the evaluation it was clear that the 'communication car', which held the keyboard and the notebook, was essential for successful operation of the system. The car was designed and built in close co-operation with our technical department. It is now used with much satisfaction on our adult and paediatric critical care units.

This keyboard is certainly not a panacea for all communication

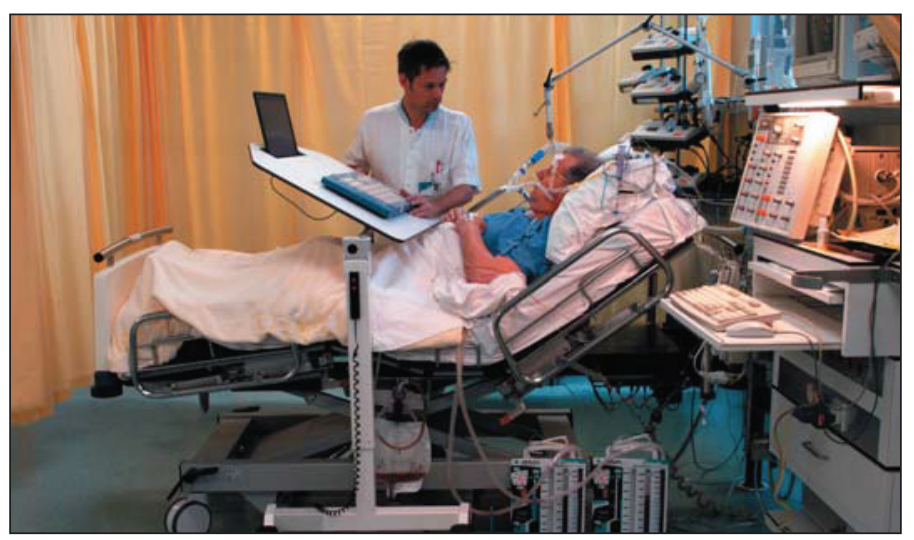

Photo 3. The 'communication car' is mobile. The height and surface angle are both adjustable so that the patient can operate the aid when lying in bed as well as sitting in a chair

\begin{tabular}{|c|c|c|c|c|}
\hline \multicolumn{5}{|c|}{ Letter board } \\
\hline \multirow{2}{*}{ Are you satisfied with it? } & Patients & Yes $=3$ & $\mathrm{No}=3$ & Yes/No $=1$ \\
\hline & Nurses & Yes $=2$ & $\mathrm{No}=3$ & Yes/No $=1$ \\
\hline \multirow{2}{*}{$\begin{array}{l}\text { How much effort is needed in order for } \\
\text { you/the patient to make yourself/himself } \\
\text { understood? }\end{array}$} & Patients & Less $=1$ & More $=2$ & Less/More $=2$ \\
\hline & Nurses & Less $=2$ & More $=4$ & \\
\hline Is it easy to operate? & Patients & Simple $=2$ & Difficult $=2$ & $\begin{array}{l}\text { Simple/ } \\
\text { Difficult }=2\end{array}$ \\
\hline \multicolumn{5}{|c|}{ Keyboard } \\
\hline \multirow{2}{*}{ Are you satisfied with it? } & Patients & Yes $=7$ & $\mathrm{No}=1$ & \\
\hline & Nurses & Yes $=6$ & $\mathrm{No}=0$ & $\mathrm{Yes} / \mathrm{No}=1$ \\
\hline \multirow{2}{*}{$\begin{array}{l}\text { How much effort is needed in order for } \\
\text { you/the patient to make yourself/himself } \\
\text { understood? }\end{array}$} & Patients & Less $=5$ & More $=2$ & Less/More $=1$ \\
\hline & Nurses & Less $=5$ & More $=0$ & Less/More $=2$ \\
\hline Is it easy to operate? & Patients & Simple $=5$ & Difficult $=2$ & $\begin{array}{l}\text { Simple/ } \\
\text { Difficult }=2\end{array}$ \\
\hline $\begin{array}{l}\text { Would you use the 'intelligent' keyboard } \\
\text { if bought as a communication aid? }\end{array}$ & Nurses & Yes $=7$ & $\mathrm{No}=0$ & \\
\hline
\end{tabular}

Table 2. Results of the evaluation. 
problems with ventilated patients. However, it has shown to be an effective aid for improving communication compared with the alphabetical letter board, and patients can express their needs more effectively because of the immediate visual feedback. On the strength of our evaluation, the 'intelligent' keyboard was purchased for use in our practice.

N.B. A version of this article was published originally in Dutch: Van Grunsven A \& Van den Boogaard M. (2003) Een nieuw communicatiehulpmiddel bij beademde patiënten. Kritiek 21 (4) 3-7.

\section{REFERENCES}

Bergbom-Engberg I \& Haljamae H. (1989) Assessment of patients' experience of discomforts during respirator therapy. Critical Care Medicine 17 (10), 1068-1072.

Bloo GJA. (2001) Overleven op een intensive care-afdeling na een trauma Deel 1:Literatuurstudie. [Surviving on an intensive care unit after a trauma. Part 1: literature review]. Kritiek 19 (5) 3-9. [Dutch]

Hafsteindottir TB. (1996) Patient's experiences of communication during the respirator treatment period. Intensive and Critical Care Nursing 12 (5), 261-271.

Usher K \& Monkley D. (2001) Effective communication in an intensive care setting: nurses' stories. Contemporary Nurse 10 (1-2), 91-101.

Wojnicki-Johansson G. (2001) Communication between nurse and patient during ventilator treatment: patient reports and RN 